\title{
Epidemiological Profile of Hyperferritinemia in the Military Hospital Moulay Ismail of Meknes, Morocco
}

\author{
${ }^{1}$ Department of Biochemistry-Toxicology, Moulay Ismail military hospital, Meknes, Morocco \\ ${ }^{2}$ Mohamed V University, Faculty of Sciences of Rabat, Morocco \\ ${ }^{3}$ Mohamed V University, Faculty of Medicine and Pharmacy of Rabat, Morocco \\ ${ }^{4}$ Sidi Mohamed Ben Abdellah University, Faculty of Medicine and Pharmacy of Fez, Morocco
}

M. Mahha ${ }^{1}$, R. Hendi ${ }^{1}$, A. Laraqui ${ }^{2}$, N. El Mouh ${ }^{1}$, L. Balouche ${ }^{1},{ }^{3}$, Y. Bamou ${ }^{1},{ }^{3}$, F. El Boukhrissi ${ }^{1},{ }^{4 *}$

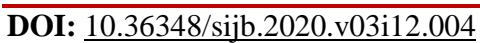

| Received: 14.12.2020 | Accepted: 22.12.2020 | Published: 25.12.2020

*Corresponding author: Fatima El Boukhrissi

\section{Abstract}

Introduction: Hyperferritinemia occurs in several medical conditions. The most prevalent underlaying causes are kidney and liver diseases, infections and tumors. The objective of our study was to establish the epidemiological profile of hyperferritinemia among patients consulting cases who attends the Military Hospital Moulay Ismail of Meknes. Materials and methods: In this study, we have enrolled all patients whose blood level of ferritin are above $600 \mu \mathrm{g} / 1$ measured on Cobas ${ }^{\circledR} 6000$ Analyzer, during a period of 12 months. Results: A total of 413 patients had values greater than $600 \mu \mathrm{g} / \mathrm{l}$, which corresponds to a percentage of $7.37 \%$. The average age was 44 years \pm 8 years (18-70). The H/F sex ratio was 1.27 . The mean rate of ferritin serum level was $1123 \mu \mathrm{g} / \mathrm{l}$. Patients with hyperferritinemia were mostly outpatients in $76.7 \%$ of cases. Referred patients comes from internal medicine department $(9.4 \%)$, nephrology (7\%), gastrology (3.2\%), oncology (2.7\%), endocrinology and hematology (2.4\%), dermatology (1.9\%) and rheumatology $(1.2 \%)$. The distribution of etiologies was as following: infections $(56 \%)$, nephropathies $(31.5 \%)$, systemic diseases (17.5\%), liver diseases (15\%), diabetes $(8.5 \%)$, hemopathies $(7.5 \%)$, hemochromatosis $(7 \%)$ and neoplasia (5\%). More than the half of patients $(57 \%)$ had multiple causes simultaneously. The most common causes associations in patients with hyperferritinemia were respectively: infections-nephropathies (24\%), infections-systemic diseases (14\%) and infections-nephropathies-diabetes (6.5\%). Discussion and Conclusion: Infections and kidney diseases dominated the etiological spectrum of hyperferritinemia in our population. However, the underlying causes remain various, which makes hyperferritinemia a poor specific marker for disease diagnosis.

Keywords: Hyperferritinemia, ferritin level, Blood iron, Morocco.

Copyright (C) 2020 The Author(s): This is an open-access article distributed under the terms of the Creative Commons Attribution 4.0 International License (CC BY-NC 4.0) which permits unrestricted use, distribution, and reproduction in any medium for non-commercial use provided the original author and source are credited.

\section{INTRODUCTION}

Ferritin is an iron storage glycoprotein, found in the cytoplasm of many cells such as erythrocytes, leukocytes, hepatocytes, kidney cells, heart cells, testis, lungs and placenta. It is made up of 24 protein subunits composed of 2 types $\mathrm{H}$ and $\mathrm{L}$, arranged in the form of a hollow sphere. The nucleus is capable of storing up to 4,500 atoms of ferric iron [1].

Ferritin is an iron storage protein that can be mobilized in response to the body's needs. Its serum concentration generally reflects the state of iron reserves. This parameter is closely correlated with tissue iron reserves, particularly the load on the liver and the reticulo-endothelial system. While the decrease in serum ferritin is a specific marker for iron deficiency, its increase can be seen in several pathologies with iron overload (primary or secondary) or without iron overload (mainly hepatopathies, nephropathies, diseases of the system and malignant tumors) $[2,3]$.

Hyperferritinemia is routinely observed among patients with a variable prevalence of 16 to $46 \%$ depending on the authors [4]. It can be caused by one or more associated pathologies. The etiological diagnosis is often easy on condition of following the correct clinical and paraclinical approach, thus allowing adequate management of the hyperferritinemic patient.

The objective of our study is to assess the prevalence of hyperferritinemia in a Moroccan population consulting at the Moulay Ismail military hospital in Meknes. Then to research the etiologies of hyperferritinemia, to analyze the epidemiological and clinical characteristics of hyperferritinemic patients and 
to study the relationship between the level of ferritinemia and the different etiologies.

\section{MATERIALS AND METHODS}

This is a retrospective study carried out in the biochemistry-toxicology laboratory of the Moulay Ismail Military Hospital (HMMI) in Meknes over a 12month period spanning the entire year 2018. During this period, all serum ferritin assay requests were collected. All patients with a ferritin value> $600 \mu \mathrm{g} / \mathrm{l}$ were selected. For patients with multiple serum ferritin values $>600 \mu \mathrm{g} / 1$, the higher value was retained. Only patients on iron supplementation or who had received a transfusion within 6 months of the start of the study were excluded.

The ferritin assay was carried out by electrochemiluminescence (ECLIA) on Cobas ${ }^{\circledR} 6000$ from Roche Diagnostic ${ }^{\circledR}$. Ferritin is sandwiched between two monoclonal antibodies (Ig), one labeled with biotin and the other with ruthenium. The addition of the microparticles sensitized by streptavidin makes it possible to capture the ferritin complex bound to Ig. The complex is picked up on an electrode and the unbound free form is removed by Procell M. Applying the voltage to the electrode allows the emission of chemiluminescence which will be measured by a photomultiplier. Normal values for ferritin are 30 to 300 $\mu \mathrm{g} / 1$ in men and 20 to $200 \mu \mathrm{g} / 1$ in women.

The medical records of these patients were consulted at the requesting services to collect demographic data (age, sex) and the etiological diagnosis retained by the attending physician. In addition, we systematically looked for whether the patients presented one or more pathologies known to cause hyperferritinemia. The underlying etiologies were not considered to be mutually exclusive. Thus, for patients with several conditions, all etiologies were retained.

Furthermore, patients with a single etiology were studied separately to assess the prevalence of hyperferritinemia associated with each etiology. Hyperferritinemic patients have been classified into three groups according to the level of ferritin:

- Group 1: patients with moderately elevated ferritin (600-1000 $\mu \mathrm{g} / \mathrm{l})$,

- Group 2: patients with significant ferritin (1000$1500 \mu \mathrm{g} / \mathrm{l})$

- Group 3 of patients with major ferritin (> 1500 $\mu \mathrm{g} / \mathrm{l})$.

Quantitative variables were expressed as mean \pm standard deviation. Qualitative variables were expressed as a percentage. The comparison of the means was carried out by Student's t test. We have retained the $\mathrm{p}$ value $<0.05$ as the significance threshold.

\section{RESULTS}

During the study period, 5,600 sera reached the biochemistry-toxicology laboratory of the HMMI in Meknes for determination of ferritin. Among the samples analyzed, 413 showed ferritin values greater than $600 \mu \mathrm{g} / \mathrm{l}$, corresponding to a percentage of $7.37 \%$ excluding duplicates.

The demographic characteristics of the study population and the distribution of ferritin values into 3 groups according to the departments are shown in Table-1.

Table-1: Demographic characteristics and prescribing services of the hyperferritinemic population divided into 3 groups according to the value of ferritinemia

\begin{tabular}{|c|c|c|c|c|}
\hline Variable & Percentage (\%) & G1: Ferritine & G2: Ferritine & G3: Ferritine \\
\hline & & $600-1000 \mu \mathrm{g} / \mathrm{l}$ & $1000-1500 \mu \mathrm{g} / \mathrm{l}$ & $>1500 \mu \mathrm{g} / \mathrm{l}$ \\
\hline Numbers & 413 & $\mathrm{~N}=215$ & $N=143$ & $\mathrm{~N}=55$ \\
\hline Age (years) & $43 \pm 11$ & $45 \pm 6$ & $38 \pm 9$ & $53 \pm 12$ \\
\hline \multicolumn{5}{|l|}{ Sex } \\
\hline Male & $55,90 \%$ & 129 & 65 & 37 \\
\hline Female & $44,10 \%$ & 86 & 78 & 18 \\
\hline \multicolumn{5}{|l|}{ Requesting service } \\
\hline outpatients & $69,72 \%$ & 178 & 106 & 7 \\
\hline Internal Medicine & $9,44 \%$ & 7 & - & 32 \\
\hline Nephrology & $7,05 \%$ & 11 & 15 & - \\
\hline Clinical hematology & $2,42 \%$ & 4 & - & 6 \\
\hline Endocrinology & $2,42 \%$ & 10 & - & - \\
\hline Gastrology & $3,14 \%$ & - & 13 & - \\
\hline Rheumatology & $1,21 \%$ & 5 & - & - \\
\hline Dermatology & $1,94 \%$ & - & 8 & - \\
\hline Oncology & $2,66 \%$ & - & - & 11 \\
\hline
\end{tabular}

The mean age of the patients was $44 \pm 8$ years with extremes of 18 years and 70 years. The sex ratio $\mathrm{M}$
/ $\mathrm{F}$ was 1.27 with 231 men and 182 women. The mean serum ferritin level was $1123 \mu \mathrm{g} / \mathrm{l}$. Almost half of the 
patients $(52 \%)$ had moderately high hyperferritinemia (600-1000 $\mu \mathrm{g} \quad / \quad 1), \quad 35 \%$ had significant hyperferritinemia (1000-1500 $\mu \mathrm{g} / \mathrm{l})$ and (13\%) major hyperferritinemia (>1500 $\mu \mathrm{g} / \mathrm{l}$ ). 1). The hyperferritinemic patients were mainly outpatients with $(69.7 \%)$. The rest of the patients came from the following departments: internal medicine (9.4\%), nephrology $(7 \%)$, gastrology $(3.2 \%)$, oncology $(2.7 \%)$, endocrinology and hematology (2.4\%), dermatology $(1.9 \%)$ and rheumatology (1.2\%).

The distribution of the different etiologies within the three groups is shown in (Table-2). The most common cause of hyperferritinemia was infection, present in $(56 \%)$ of patients, followed by nephropathies $(31.5 \%)$, systemic diseases $(17.5 \%)$, liver disease (15\%), diabetes (8.5\%), hemopathies (7.5\%), hemochromatosis $(7 \%)$ and neoplasia (5\%).

The systemic diseases diagnosed in our series were represented by Still's disease ( 85 patients) and rheumatoid arthritis (26 cases). The most frequently found hepatopathies were: hepatitis C (37 cases), hepatitis B (30 cases), cirrhosis (17 cases) and hepatic steatosis (13 cases). Concerning neoplasia found in our series: cutaneous lymphoma (16 cases), gastric adenocarcinoma (9 cases) and colorectal cancer (6 cases). Blood diseases were represented by chronic myeloid leukemia (24 cases), acute leukemia (15 cases), and aplastic anemia (10 cases).

In addition, we found that more than half $(57 \%)$ of patients had multifactorial etiologies. Each patient can then be found in several etiological classes. Thus, we studied the number of etiology or underlying cause according to the serum ferritin level (Table-2). The most common associations in hyperferritinemic patients were infection-nephropathy (24\%), infectionsystem disease (14\%), and infection-nephropathydiabetes $(6.5 \%)$, respectively.

Table-2: The distribution of pathologies and the number of pathologies responsible for hyperferritinemia in the 3 groups (for patients with several conditions, all etiologies were retained)

\begin{tabular}{|c|c|c|c|c|c|}
\hline & Percentage & $\begin{array}{l}\text { G1: Ferritine } \\
(600-1000 \mu g / l) \\
N=215\end{array}$ & $\begin{array}{l}\text { G2: Ferritine } \\
(1000-1500 \mu \mathrm{g} / \mathrm{l}) \\
\mathrm{N}=143\end{array}$ & $\begin{array}{l}\text { G3: Ferritine } \\
(>1500 \mu \mathrm{g} / \mathrm{l}) \\
\mathrm{N}=55\end{array}$ & $\mathbf{p}$ \\
\hline $\begin{array}{l}\text { Etiological diagnosis Infections } \\
\text { Nephropathies } \\
\text { System diseases } \\
\text { Hepatopathy } \\
\text { Neoplasia } \\
\text { Hemopathy } \\
\text { Diabetes } \\
\text { Hemochromatosis }\end{array}$ & $\begin{array}{l}56 \% \\
31,5 \% \\
17,5 \% \\
15,3 \% \\
4,9 \% \\
7,8 \% \\
8,2 \% \\
6,9 \%\end{array}$ & $\begin{array}{l}196 \\
112 \\
42 \\
64 \\
- \\
1 \\
34 \\
15\end{array}$ & $\begin{array}{l}141 \\
73 \\
31 \\
33 \\
18 \\
16 \\
18 \\
23\end{array}$ & $\begin{array}{l}16 \\
14 \\
38 \\
- \\
13 \\
32 \\
- \\
6\end{array}$ & \\
\hline $\begin{array}{l}\text { Number of pathologies } \\
1 \\
2 \\
3 \\
\geq 4\end{array}$ & $\begin{array}{l}177(42,86 \%) \\
190(46 \%) \\
46(11,13 \%) \\
-\end{array}$ & $\begin{array}{l}92 \\
104 \\
21 \\
-\end{array}$ & $\begin{array}{l}51 \\
74 \\
14 \\
- \\
\end{array}$ & $\begin{array}{l}34 \\
12 \\
11 \\
- \\
\end{array}$ & $\begin{array}{l}<0.05 \\
<0.01\end{array}$ \\
\hline
\end{tabular}

Almost $42 \%$ of patients had a single etiology of hyperferritinemia, these were studied separately to assess the level of ferritinemia associated with each etiology (Table-3). Thus, infection was the leading cause of hyperferritinemia (32\%), followed by nephropathies (27\%), systemic diseases (11\%), liver disease $(9 \%)$ and diabetes $(7,5 \%)$. Finally, blood diseases, neoplasms and hemochromatosis accounted for $(5 \%),(4.5 \%)$ and $(3.5 \%)$ respectively.

Table-3: The distribution of ferritin values according to the etiologies in patients whose hyperferritinemia is due to a single pathology

\begin{tabular}{|l|l|l|l|}
\hline Etiological diagnosis & $\mathbf{( \% )}$ & $\begin{array}{l}\text { Ferritine }(\boldsymbol{\mu g} / \mathbf{l}) \\
\text { Mean +/- SD }\end{array}$ & $\begin{array}{c}\text { Ferritine }(\boldsymbol{\mu g} / \mathbf{l}) \\
\text { Interval }(\mathbf{m i n}-\mathbf{m a x})\end{array}$ \\
\hline Infections & 32 & $883,80+/-197,64896,45+/-276,78$ & $605-1559620-1957$ \\
Nephropathies & 27 & $1322,53+/-582,73822,16+/-148,87$ & $634->2000612-1016$ \\
System diseases & 11 & $749,5+/-96,77$ & $676-823$ \\
Hepatopathy & 9 & $962,5+/-206,17$ & $745->1390$ \\
Diabetes & 8 & $1806,40+/-695,58$ & $1028->2000$ \\
Hemopathy & 5 & $1085+/-110,70$ & $871-1299$ \\
Neoplasia & 4,5 & & \\
Hemochromatosis & 3,5 & & \\
\hline
\end{tabular}




\section{DISCUSSION}

Although the level of serum ferritin is mainly regulated by the quantity of intracellular iron, it is also regulated by various stimuli such as cytokines, growth factors, hormones, oxidative stress, and hypoxia. Several studies have also shown that ferritin levels can vary in inflammation, immunity disorders and cancer $[5,7]$. Thus, hyperferritinemia can be encountered during the onset of several conditions which can coexist or even overlap, which makes it a very unspecific marker, especially when the increase is moderate (less than $1500 \mu \mathrm{g} / 1)$ [5].

The average ferritin level in our series was $971.2 \mu \mathrm{g} / 1+/-312.17$. This is a relatively moderate increase in blood ferritin levels in most patients. Solid tumors and system diseases and in a second-degree nephropathy were the main etiologies found in severe hyperferritinemia cases $(\geq 1900 \mu \mathrm{g} / 1)$. This result is comparable to what has been reported in the literature with solid tumors and repeated transfusions as the primary cause of severe hyperferritinemia [8, 9]. Indeed, several patients with kidney damage in our series do not routinely benefit from erythropoietin treatment and continue to undergo periodic transfusions.

In our study, we observed that $(57 \%)$ of hyperferritinemic patients presented with comorbidities with association frequencies of (24\%) for infection-nephropathy, (14\%) for infection-system disease and $(8 \%)$ for infection-nephropathy-diabetes. This rate is comparable to studies reported in the literature which vary from 16.8 to $46 \%$ [4, 7, 10, 12]. However, this result does not elucidate the exact role of each etiology in cases of hyperferritinemia. Regarding the study of patients with a single cause of hyperferritinemia, infection was the leading cause of hyperferritinemia both in the general population and in those with a single identified cause of hyperferritinemia with a rate of $32 \%$ of cases.

The importance of the cases of infection in our series is consistent with data from the literature, which reports rates ranging from $24 \%$ [14] to $45 \%$ [4]. This rate would also be linked to the mode of recruitment in our series. Indeed, over $69 \%$ of the participants were external consultants with an average age of 43 years. These are therefore patients with rather acute and relatively benign conditions. It is also useful to remember that Morocco is still in epidemiological transition and where infection remains one of the main causes of consultation.

Nephropathies and system diseases were responsible for $26.5 \%$ and $11 \%$ of hyperferritinemia cases, respectively, a rate comparable to that reported by Senjo et al., $23.6 \%$ and $14.5 \%$ while Le page et al., only reported a rate of $4.2 \%$ and $5.2 \%$ respectively [ 4 , 11]. These variations may also be related to the recruitment of populations in the different studies.
Indeed, the low rate of nephropathies and system diseases reported by Le page et al., is linked to the use of erythropoietin and the reduction of transfusions in the patients with renal failure included in their study.

The origin of the hyperferritinemia found in people with infection, nephropathy or disease of the system, or nearly $70 \%$ in our series, is believed to be linked to inflammation. In fact, inflammatory pathways are linked to the regulation of hepcidin, a key hormone that regulates iron homeostasis by controlling the functioning of ferroportin. Hepcidin binds to ferroportin and inactivates it by internalizing and degrading it inside the cell resulting in decreased absorption of iron from the intestine and sequestration of iron in the reticulosystem. endothelial, thus limiting the availability of iron in the circulation [14]. This is because hepcidin acts from the acute phase of inflammation and its production is increased by the liver in response to inflammatory cytokines (especially IL-6) [15]. Consequently, during an infection, iron will be kept as much as possible in the intracellular compartment in order to withdraw it from microbial metabolism and thus interfere with its multiplication cycle [16]. This mechanism could be at least partially responsible for the hyperferritinemia observed in patients with chronic infections, chronic renal failure, autoimmune diseases and malignant tumors.

Liver disease was responsible for only $9.5 \%$ of the hyperferritinemia in our series. The origin of this hyperferritinemia may be due, at least partially, to the activation of macrophages leading to disruption of iron storage proteins [13]. This is an intermediate rate compared to the literature where several studies have reported rates ranging from $4.2 \%$ to $35.5 \%[4,11]$. This result is probably related to the origin of the participants in our series where only $3.14 \%$ of patients were referred by the gastrology department. Diabetes was responsible for $8 \%$ of hyperferritinemia cases. This hyperferritinemia is thought to have its origin in the phenomenon of insulin resistance. Indeed, several studies have reported moderate hyperferritinemia in cases of insulin resistance and hepatic steatosis $[17,18]$.

Blood diseases and solid tumors were found in $5 \%$ and $4.5 \%$ of hyperferritinemia cases in our series, respectively. This hyperferritinemia is thought to be due to the multiple transfusions that some patients have undergone but also to the probable interference of the tumor process with iron homeostasis. Finally, hemochromatosis accounted for only $3.5 \%$ of cases. The origin of this hyperferritinemia is due to an iron overload, the primitive form of which is due to mutations in the gene responsible for the production of the HFE protein which promotes excessive iron absorption in the enterocytes [19].

\section{CONCLUSION}

Although ferritin level is primarily regulated by intracellular iron load, it is also controlled by various 
stimuli. Therefore, serum ferritin is increased under various conditions. This is the first study carried out in the Meknes region to draw up the spectrum of etiology encountered in our hospital in order to guide our clinicians in their diagnostic approach. Thus, in our hospital, the etiological spectrum is dominated by major causes represented by infection and nephropathies followed by diseases of the system, blood diseases and diabetes. The multiplication of the etiologies found makes ferritin a poorly specific marker, especially in mild to moderate hyperferritinemia. Only severe hyperferritinemia could be suggestive of tumor process or system disease.

Declaration of interest: The authors declare that they have no conflict of interest in connection with this article.

\section{REFERENCES}

1. Harrison, P. M., \& Arosio, P. (1996). The ferritins: molecular properties, iron storage function and cellular regulation. Biochimica et Biophysica Acta (BBA)-Bioenergetics, 1275(3), 161-203.

2. Beaumont, C., \& Karim, Z. (2012). Iron metabolism: State of the art. La Revue de Médecine Interne, 34(1), 17-25.

3. Damade, R., Rosenthal, E., \& Cacoub, P. (2000, May). Hyperferritinemia. In Annales de medecine interne (Vol. 151, No. 3, pp. 169-177).

4. Senjo, H., Higuchi, T., Okada, S., \& Takahashi, O. (2018). Hyperferritinemia: causes and significance in a general hospital. Hematology, 23(10), 817822 .

5. Addison, G. M., Beamish, M. R., Hales, C. N., Hodgkins, M., Jacobs, A., \& Llewellin, P. (1972). An immunoradiometric assay for ferritin in the serum of normal subjects and patients with iron deficiency and iron overload. Journal of Clinical Pathology, 25(4), 326-329.

6. Knovich, M. A., Storey, J. A., Coffman, L. G., Torti, S. V., \& Torti, F. M. (2009). Ferritin for the clinician. Blood reviews, 23(3), 95-104.

7. Lee, M. H., \& Means, R. T. (1995). Extremely elevated serum ferritin levels in a university hospital: associated diseases and clinical significance. The American journal of medicine, 98(6), 566-571.

8. Crook, M. A., \& Walker, P. L. (2013). Extreme hyperferritinaemia; clinical causes. Journal of clinical pathology, 66(5), 438-440.

9. Sackett, K., Cunderlik, M., Sahni, N., Killeen, A. A., \& Olson, A. P. (2016). Extreme hyperferritinemia: causes and impact on diagnostic reasoning. American journal of clinical pathology, 145(5), 646-650.

10. Moore Jr, C., Ormseth, M., \& Fuchs, H. (2013). Causes and significance of markedly elevated serum ferritin levels in an academic medical center. JCR: Journal of Clinical Rheumatology, 19(6), 324-328.

11. Le Page, L., Leflon, P., Mahévas, M., Duhaut, P., Smail, A., Salle, V., ... \& Ducroix, J. P. (2005). Spectre étiologique des hyperferritinémies. La Revue de médecine interne, 26(5), 368-373.

12. Narayanan, D., \& Waise, A. (2013). Causes of hyperferritinaemia. Ann Clin Biochem. 50:381382 .

13. Kotoh, K., Ueda, A., Tanaka, M., Miyazaki, M., Kato, M., Kohjima, M., ... \& Takayanagi, R. (2009). A high prevalence of extreme hyperferritinemia in acute hepatitis patients. Hepatic medicine: evidence and research, 1, 1-9.

14. Nakanishi, T., Hasuike, Y., Otaki, Y., Kida, A., Nonoguchi, H., \& Kuragano, T. (2011). Hepcidin: another culprit for complications in patients with chronic kidney disease?. Nephrol Dial Transplant, 26:3092-100.

15. Nemeth, E., Rivera, S., Gabayan, V., Keller, C., Taudorf, S., Pedersen, B. K., \& Ganz, T. (2004). IL-6 mediates hypoferremia of inflammation by inducing the synthesis of the iron regulatory hormone hepcidin. The Journal of clinical investigation, 113(9), 1271-1276.

16. Gluckman, P., Beedle, A., Buklijas, T., Low, F., \& Hanson, M. (2016). Principles of evolutionary medicine. Oxford University Press.

17. Fargion, S., Mattioli, M., Fracanzani, A. L., Sampietro, M., Tavazzi, D., Fociani, P., ... \& Fiorelli, G. (2001). Hyperferritinemia, iron overload, and multiple metabolic alterations identify patients at risk for nonalcoholic steatohepatitis. The American journal of gastroenterology, 96(8), 2448-2455.

18. Mendler, M. H., Turlin, B., Moirand, R., Jouanolle, A. M., Sapey, T., Guyader, D., ... \& Deugnier, Y. (1999). Insulin resistance-associated hepatic iron overload. Gastroenterology, 117(5), 1155-1163.

19. Feder, J. N., Penny, D. M., Irrinki, A., Lee, V. K., Lebrón, J. A., Watson, N., ... \& Schatzman, R. C. (1998). The hemochromatosis gene product complexes with the transferrin receptor and lowers its affinity for ligand binding. Proceedings of the National Academy of Sciences, 95(4), 1472-1477. 